\title{
Synthesis and properties of new polyimide/clay nanocomposite films
}

\author{
YAGOUB MANSOORI*, SOMAYEH SHAH SANAEI, MOHAMMAD-REZA ZAMANLOO, \\ GHOLAMHASSAN IMANZADEH and SEYED VAHID ATGHIA \\ Department of Applied Chemistry, Faculty of Science, University of Mohaghegh Ardabili, Ardabil 56199-11367, Iran
}

MS received 24 February 2012; revised 10 May 2012

\begin{abstract}
A series of polymer-clay nanocomposite (PCN) materials consisting of polyimide and typical clay were prepared by solution dispersion. Quaternary alkylammonium modified montmorillonite, Cloisite 20A, was used as organoclay. Poly(amic acid) solution was prepared from the reaction of benzophenone-4, $\mathbf{4}^{\prime}, 3,3^{\prime}$-tetracarboxylic dianhydride and 2-(5-(3,5-diaminophenyl)-1,3,4-oxadiazole-2-yl) pyridine in dimethylacetamide. Thermal imidization was performed on poly(amic acid)/organoclay dispersion in a regular temperature-programmed circulation oven. The study of interlayer $d$-spacing with $\mathrm{X}$-ray diffraction pattern indicates that an exfoliated structure may be present in the nanocomposite $1 \%$. Intercalated structures were obtained at higher organoclay loadings. Nanocomposites were studied using thermogravimertic analysis and differential scanning calorimetry. Nanocomposites exhibit higher glass transition temperature and improved thermal properties compared to neat polyimide due to the interaction between polymer matrix and organoclay particles. The results are also compared with data of a similar work. Morphology study with scanning electron microscopy showed that the surface roughness in nanocomposite $1 \%$ increased with respect to pristine polyimide. Solvent uptake measurements were also carried out for the prepared materials. Maximum solvent adsorption was observed for dimethyl sulfoxide (DMSO). It was found that the solvent uptake capacity decreased with increasing clay content.
\end{abstract}

Keywords. Polyimide; poly(amic acid); nanocomposite; organoclay.

\section{Introduction}

Polymer-clay nanocomposites have gained considerable attention in recent years. Clay contains negatively charged layers bound by ionic bonding with metal cations such as $\mathrm{Na}^{+}$. Montmorillonite (MMT) is one of the most widely used layered silicates for the preparation of nanocomposites. To ensure better dispersion of clay particles in the organic polymer matrix, organic modification of clay is achieved through the exchange of sodium ions with organic alkylammonium ions. This modification makes the normally hydrophilic clay hydrophobic and potentially more compatible with the polymer being used in preparation of the polymer-clay nanocomposites (Morgan and Gilman 2003). The homogeneous dispersion of organically modified clays in polymer matrices could lead to enhanced thermal stability (Phang et al 2005; Zhao and Wang 2006; Jin and Chang 2008; Rubal et al 2008), mechanical properties (Gintert et al 2007; Jia et al 2008; Stefanescu et al 2008; Njuguna et al 2008; Mansoori et al 2010a,b, 2011a), gas barrier (Yudin et al 2007; Huang et al 2008), dielectric properties ( $\mathrm{Gu}$ et al 2001) and solvent resistance (Huang et al 2001) compared to virgin polymers.

Aromatic polyimides have been well known as highperformance polymers with excellent thermal stability, good resistance towards organic solvents and improved mechani-

\footnotetext{
*Author for correspondence (ya_mansoori@yahoo.com)
}

cal properties. They have been accepted as the most useful super engineering plastics that have found many applications in wide ranging areas of modern industries (Liaw and Liaw 1998; Imai et al 2002). Aromatic polyimides have been found in a wide range of applications, especially in aerospace and electrical/electronic industries (Xu et al 2003; Shin et al 2003; Hsu and Fan 2004; Chi et al 2007; Nguyen et al 2007), gas separation (Chatzidaki et al 2007), cell processing and biochips designing (Matsumoto et al 2008), coatings and composites (Köytepe et al 2008).

Nanoscale composites of polyimides with organoclay have been studied extensively. Yano et al $(1993,1997)$ prepared polyimide-clay hybrid films with clay minerals of four different particle sizes. They studied the effect of particle size of clay minerals on the properties of hybrids. Hectrite, saponite, montmorillonite and synthetic mica were used as clay minerals. It was found that the larger size of clay particles is much more effective in improving the properties of polyimides.

Tyan et al (2000) used 4,4'-oxydianiline (ODA)-modified montmorillonite as organoclay. The poly(amic acid) was obtained from the reaction of ODA and $3,3^{\prime}, 4,4^{\prime}$ benzophenone tetracarboxylic dianhydride (BTDA). Then, the layered silicates of organoclay were intercalated with polyimide (BTDA-ODA). It was found that the modulus and maximum stress of these organoclay/BTDA-ODA nanocomposites were much higher than those of pure BTDA-ODA. Liang et al (2003) used thermally stable and rigid-rod aromatic amine modifiers to modify 
MMT-layered silicate. They observed that MMT treated with these aromatic amines exhibited better dispersibility and interfacial interaction with PI matrix than that treated by aliphatic amines. Gu et al (2001) reported a new organomontmorillonite, which was developed by ion-exchange reaction of cetyl pyridinium chloride with $\mathrm{Na}^{+}$MMT, for PI hybrids. Two synthesis methods are employed for preparing PI/clay hybrids. Method I involves blending a dimethylacetamide (DMAc) solution of the diamine with a DMAc dispersion of organoclay before adding dianhydride. Method II involves blending a DMAc solution of poly(amic acid) with a DMAc dispersion of organoclay. A $3 \mathrm{wt} \%$ of organoclay concentration in the hybrid formed by method II results in optimum overall properties in terms of tensile strength, modulus, elongation, coefficient of thermal expansion and water absorption. Several approaches were examined by Delozier et al (2007) to achieve fully exfoliated polyimide/organoclay nanocomposites. The best results were obtained by using an in situ polymerization technique in which poly(amic acid)s were synthesized in the presence of organoclay. Chiang and Whang (2003) prepared polyimide $/ \mathrm{TiO}_{2}$ hybrid nanocomposite films by an in situ sol-gel process. These nanocomposite films exhibited decent optical transparency with up to $40 \mathrm{wt} \%$ of $\mathrm{TiO}_{2}$ content. Jin and Chang (2008) prepared polyimide hybrid films with excellent optical transparencies, which were almost colourless. However, transparency decreases slightly with increase in organoclay content because of agglomeration of clay particles. Huang et al (2008) reported the preparation of high-performance polyimide-clay nanocomposite materials based on a dual intercalating agent system. They observed that silicate layers are better dispersed in polymer matrices when dual intercalating agents (hexadecyltrimethylammonium bromide-4,4'-oxydianiline) are used for MMT modification.

We are interested in the synthesis of highly thermally stable polymers. It was found that thermal stability of polymers can be increased by the incorporation of oxadiazole moieties into the polymer structure (Ding et al 2002; Mansoori et al 2012d). Aromatic poly(1,3,4-oxadiazole)s are classified as high-performance polymers with excellent mechanical strength and stiffness. Outstanding thermal stability is ascribed to the oxadiazole ring being electronically equivalent to the phenylene ring structure, which is known to be highly thermally resistant. Thus, polymers containing 1,3,4oxadiazole moieties are considered as alternatives for the development of heat- and flame-resistant, semiconducting, fibre-forming and thermally stable membranes for gas separation purposes (Hsiao and Chiou 2001; Gomes and Nunes 2003; Souza et al 2004).

Recently, our research team successfully carried out the synthesis of POBD, which contains an oxadiazole moiety. POBD has been used for the preparation of new, poly (amideimide)s (Mansoori et al 2011b), thermally stable polyamides (Mansoori et al 2012a, b), and polyimides (Mansoori et al 2012c). It has been shown that the 2-pyridyl group adjacent to the 1,3,4-oxadiazole ring can act as a bidentate ligand

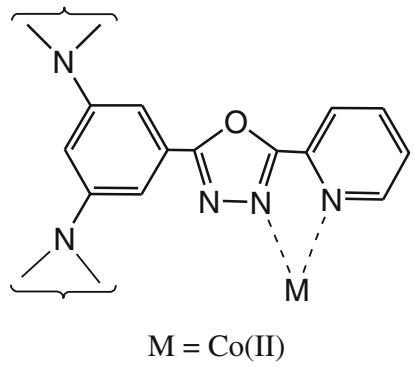

Scheme 1. Proposed schematic representation for the coordination of Co(II) ions (Mansoori et al 2012c).

toward heavy and toxic metal ions such as $\mathrm{Cu}$ (II), $\mathrm{Co}$ (II) and Cd(II) (Incarvito and Rheingold 2001; Du et al 2006). This feature is considered in designing POBD (scheme 1).

Preparation of POBD-modified organoclay and its polyimide nanocomposites for the removal of Co(II) ion have also been investigated (Mansoori et al 2011a). The present work describes the preparation and characterization of new PCNs with POBD, benzophenone-4,4',3,3'-tetracarboxylic dianhydride (BTDA), and different amounts of organoclay, Cloisite 20A. The results are compared with the previously obtained results for similar polymer matrix and POBD-treated MMT as surfactant.

\section{Experimental}

\subsection{Instruments}

IR spectra were recorded on a Buck-IR Scientific 500 Model 500 instrument. Differential scanning calorimetry (DSC) and thermogravimertic analysis (TGA) thermograms were measured with DSC PL and TGA PYRIS 1 instruments, respectively. Elemental analyses of the samples were performed with an Elemental Vario EL III instrument. Wide-angle X-ray diffraction (XRD) measurements were performed at room temperature with a Simence D500 X-ray diffractometer (Germany) by using Ni-filtered Co-K $\alpha$ radiation. The scanning rate was $1 \%$ min over a $2 \theta$ range of $2-10^{\circ}$. Scanning electron microphotographs were obtained with a LEO 1430VP instrument.

\subsection{Material}

Commercial Cloisite 20A was purchased from Southern Clay Products (Gonzales, TX). Organic diamine 2-(5-(3,5-diaminophenyl)-1,3,4-oxadiazole-2-yl) pyridine (POBD) was synthesized according to the literature (Mansoori et al 2011b). Methanol and 3,3',4,4'-benzophenone tetracarboxylic acid dianhydride were purchased from Merck and used as received. $N, N^{\prime}$-dimethylacetamide was obtained from Merck and dried over sodium hydride. 
2.2a Preparation of poly(amic acid): To a solution of POBD $(0.3166 \mathrm{~g}, 1.25 \mathrm{mmol})$ in $5.0 \mathrm{ml}$ of DMAc, was gradually added $3,3^{\prime}, 4,4^{\prime}$-benzophenone tetracarboxylic dianhydride (BTDA) $(0.4027 \mathrm{~g}, 1.25 \mathrm{mmol})$. The mixture was stirred at room temperature for $2 \mathrm{~h}$ under argon blanket, yielding a $16 \mathrm{wt} \%$ DMAc solution of poly(amic acid). After this time period, the polymer solution was poured into $40 \mathrm{ml}$ of $\mathrm{MeOH}$, refluxed for $30 \mathrm{~min}$, filtered in vacuum, washed with a 50/50 warm mixture of $\mathrm{MeOH} /$ water, and then dried in vacuum at $45^{\circ} \mathrm{C}$ for $24 \mathrm{~h}$ to give $0.6258 \mathrm{~g}$ of poly(amic acid) (87\% yield). IR (KBr, cm $\left.{ }^{-1}\right): 3500-2400$ (br), 1709 (s), 1666 (s), 1606 (s), 1545 (s), 1460 (s), 1241 (s), 852 (m).

2.2b Preparation of polyimide film: A DMAc solution of the obtained poly(amic acid) was poured on a glass plate, allowed to stand at room temperature overnight, and then heated first to $60^{\circ} \mathrm{C}$ and then to $320^{\circ} \mathrm{C}$ (heating rate of $1^{\circ} \mathrm{C} /$ $\mathrm{min})$ in a furnace. The film was then peeled off from the glass plate to obtain the PI film. IR $\left(\mathrm{KBr}, \mathrm{cm}^{-1}\right)$ : $1776(\mathrm{~m})$, 1721 (s), 1545 (w), 1362 (m), $1241(w), 1140$ (m), 857 (w), $718(\mathrm{w}), 669(\mathrm{w})$.

2.2c Preparation of poly(amic acid)/clay dispersion: Poly(amic acid)/clay composition was prepared according to method II described by $\mathrm{Gu}$ et al (2001). A typical procedure to prepare DMAc solution of poly(amic acid)/clay containing $1 \mathrm{wt} \%$ of clay is as follows: a mixture of $0.0148 \mathrm{~g}$ of Cloisite $20 \mathrm{~A}$ and $4.24 \mathrm{ml}$ of DMAc was magnetically stirred vigorously at $90^{\circ} \mathrm{C}$ for $24 \mathrm{~h}$ to yield DMAc dispersion of MMT. POBD $(0.6508 \mathrm{~g}, 2.75 \mathrm{mmol})$ was dissolved in $5 \mathrm{ml}$ DMAc. 3,3',4,4'-tetracarboxylic dianhydride (BTDA) $(0.8288 \mathrm{~g}, 2.75 \mathrm{mmol})$, was then gradually added to this solution under an argon atmosphere over $30 \mathrm{~min}$ and stirred at room temperature for $4 \mathrm{~h}$. DMAc dispersion of organoclay was added into the mixture and stirred vigorously at $30^{\circ} \mathrm{C}$ for $4 \mathrm{~h}$ to yield a $16 \mathrm{wt} \%$ DMAc solution of poly(amic acid).

2.2d Preparation of PCN film: The obtained DMAc solution of poly(amic acid)/clay was poured on a glass plate, allowed to stand at room temperature overnight, and then heated first to $60^{\circ} \mathrm{C}$ and then to $320^{\circ} \mathrm{C}$ (heating rate of $1{ }^{\circ} \mathrm{C}$ / min) in a high temperature oven. The film was then peeled off from the glass plate to obtain PCN film. 2.2e Solvent uptake measurements: The PI or the nanocomposite samples $(0.02 \mathrm{~g})$ were immersed in solvents at $25^{\circ} \mathrm{C}$ for $72 \mathrm{~h}$. After this time period, the samples were squeezed between two pieces of filter paper and weighed immediately.

\section{Results and discussion}

We recently reported the syntheses and characterization of new thermally stable poly(amide-imide)s (Mansoori et al 2011b) and polyimides (Mansoori et al 2012c) containing 1,3,4-oxadiazole-2-pyridyl pendant group. The polyimides were prepared through the reaction of 2-(5-(3,5diaminophenyl)-1,3,4-oxadiazole-2-yl) pyridine (POBD) and different dianhydrides via poly(amic acid) intermediates. Imidization of the poly(amic acid) intermediates was carried out chemically in DMAc in the presence of acetic anhydride and pyridine at $120^{\circ} \mathrm{C}$. The present study reports the synthesis of a polyimide from the reaction of POBD and BTDA via thermal imidization of the poly(amic acid) intermediate (scheme 2). Preparation of polyimide nanocomposite materials having different contents of Cloisite 20A has also been investigated.

IR spectrum of the poly(amic acid) sample (figure 1(a)) shows sharp absorption bands at $1666 \mathrm{~cm}^{-1}$ (amide I) and $1627 \mathrm{~cm}^{-1}$ (amide II), and a broad absorption band at $3400-2900 \mathrm{~cm}^{-1}$ due to amino $(\mathrm{N}-\mathrm{H})$ and hydroxyl $(\mathrm{OH})$ groups. IR absorptions appearing at approximately 1782, 1727 and $1356 \mathrm{~cm}^{-1}$ indicate the presence of imide functional groups in the polyimide film (figure 1(b)). Conversion from poly(amic acid) to polyimide was confirmed by the presence of these strong imide absorption bands and the absence of broad absorption band characteristic of amino $(\mathrm{N}-\mathrm{H})$ and hydroxyl $(\mathrm{OH})$ groups. Disappearance of amide carbonyl absorptions located at approximately 1666 and $1627 \mathrm{~cm}^{-1}$ also confirms imidization.

Solubility test results (table 1) show that the poly(amic acid) is soluble in polar aprotic solvents such as DMSO, DMAc, DMF and $N$-methyl- $Z$-pyrrolidone (NMP). For this experiment, about $0.01 \mathrm{~g}$ of the polymer sample was examined in $1 \mathrm{ml}$ of the solvent at room temperature and at elevated temperature $\left(95^{\circ} \mathrm{C}\right)$. The polyimide POBD-BTDA is partially soluble in the mentioned solvents and in chloroform at room temperature and at elevated temperatures. Both

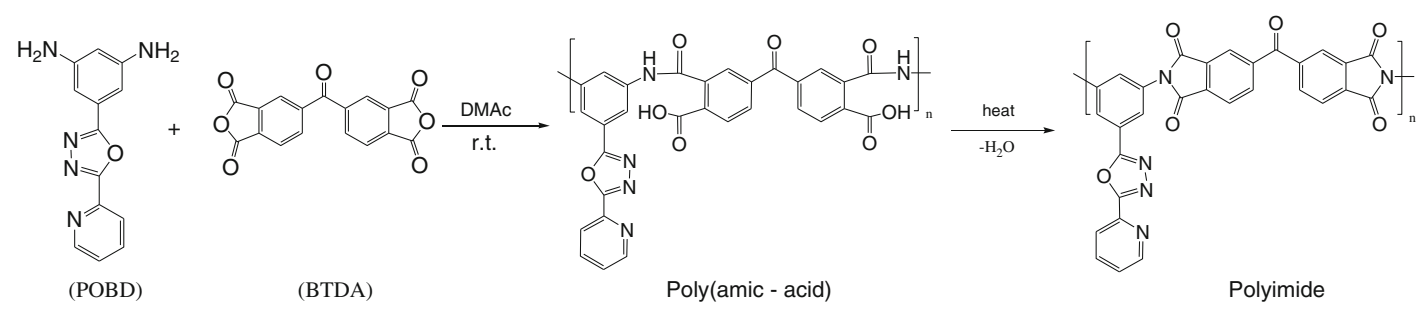

Scheme 2. Synthesis of poly(amic acid) and polyimide. 


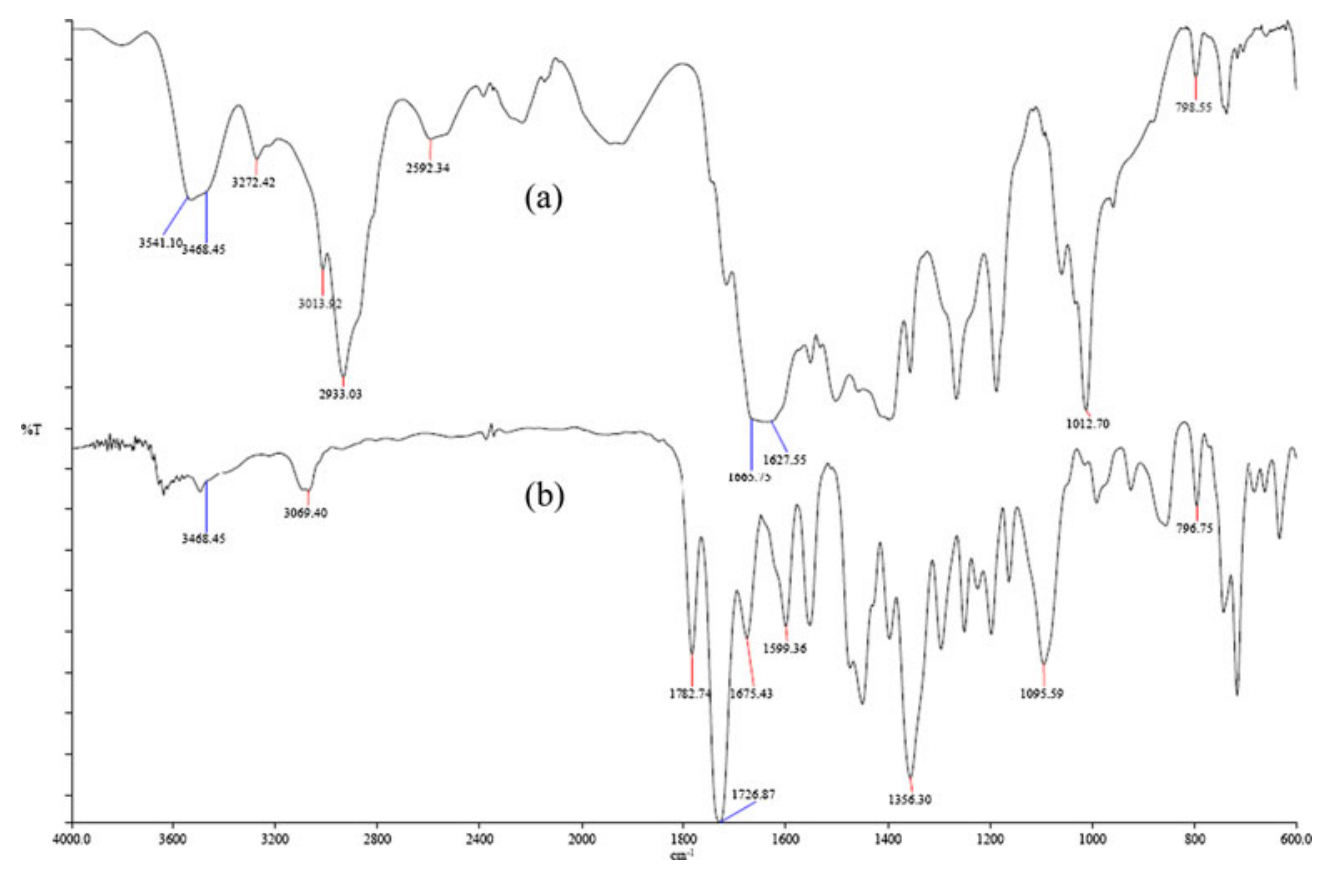

Figure 1. FT-IR spectra (KBr) of (a) poly(amic acid) and (b) polyimide.

Table 1. Solubility of poly(amic acid) and polyimide.

\begin{tabular}{lccccccccccc}
\hline Solvent & \multicolumn{1}{c}{ DMSO } & DMF & DMAc & $\mathrm{NMP}$ & $\mathrm{MeOH}$ & $\mathrm{EtOAc}$ & $\mathrm{CHCl}_{3}$ & Acetone & $\mathrm{H}_{2} \mathrm{SO}_{4}$ \\
\hline Poly(amic acid) & $R . T$. & ++ & ++ & +- & +- & -- & -- & -- & -- & ++ \\
& $\Delta$ & ++ & ++ & ++ & ++ & -- & -- & -- & -- & ++ \\
Polyimide & $R . T$. & +- & +- & +- & +- & -- & -- & -+ & -- & ++ \\
& $\Delta$ & +- & +- & +- & +- & -- & -- & -+ & -- & ++ \\
\hline
\end{tabular}

++ Soluble; -+ partially soluble and -- insoluble.

Table 2. Inherent viscosities of poly(amic acid) and polyimide solutions.

\begin{tabular}{lcc}
\hline & \multicolumn{2}{c}{ Inherent viscosity } \\
\cline { 2 - 3 } Polymer & $\eta_{\text {Inh }}(\mathrm{g} / \mathrm{dL})^{\mathrm{a}}$ & $\eta_{\text {Inh }}(\mathrm{g} / \mathrm{dL})^{\mathrm{b}}$ \\
\hline Poly(amic acid) & 0.23 & 0.42 \\
Polyimide (thermal imidization) & 0.51 & 1.23 \\
Polyimide (chemical imidization) & 0.17 & 0.42 \\
\hline
\end{tabular}

${ }^{a}$ Measured in concentrated sulphuric acid at a concentration of $0.25 \mathrm{~g} / \mathrm{dL}$ at $25 \pm 0.5^{\circ} \mathrm{C}$ and ${ }^{\mathrm{b}}$ measured in concentrated sulphuric acid at a concentration of $0.125 \mathrm{~g} / \mathrm{dL}$ at $25 \pm 0.5^{\circ} \mathrm{C}$.

the poly(amic acid) and polyimide are soluble in concentrated sulphuric acid and insoluble in boiling methanol, ethyl acetate and acetone.

Inherent viscosities of poly(amic acid) and polyimide solutions in concentrated sulphuric acid are given in table 2 . As shown in the table, inherent viscosity of the polyimide prepared via thermal imidization is higher than that for the polyimide prepared via chemical imidization. Lower viscosities for solutions with higher concentration can be related to entanglement of polymer chains. A polymer molecule in a solvent of low concentration has a better interaction with solvent molecules and writhes freely among its neighbours, while in a concentrated solution such freedom would be reduced and could eventually lead to aggregation (Gandhi 
and Williams 1971). The prepared poly(amic acid) and polyimide were also characterized by elemental analysis (CHN), the results of which are shown in table 3 . The calculated and observed values for $\mathrm{CHN}$ analyses are in good agreement.

A procedure for the preparation of polyimide/clay nanocomposites by thermal imidization according to method II reported by Gu et al (2001) is shown in scheme 3 .

An appropriate amount of Cloisite 20A was introduced into DMAc and stirred magnetically for $24 \mathrm{~h}$ at $90^{\circ} \mathrm{C}$. In another reaction vessel, an equimolar ratio of BTDA was gradually added into a POBD solution in DMAc at room temperature over a period of $30 \mathrm{~min}$ under argon blanket. The contents of the two flasks were combined and stirred vigorously at $30^{\circ} \mathrm{C}$ for $4 \mathrm{~h}$ to yield a DMAc solution of poly(amic acid)/clay. The resulting solution was then poured onto a glass plate, allowed to stand at room temperature overnight, and then heat treated in a high temperature oven at a temperature range of $60-320^{\circ} \mathrm{C}$ (heating rate of $1{ }^{\circ} \mathrm{C} / \mathrm{min}$ ).

Wide angle X-ray diffraction (WAXRD) patterns of $\mathrm{Na}$ MMT, Cloisite 20A and PCN films with various clay contents are shown in figure 2 . The spacing between silicate layers, $d$, can be calculated from the peak positions by using Bragg's law:

$$
n \lambda=2 d \sin \theta
$$

Table 3. Elemental analysis of poly(amic acid) and polyimide.

\begin{tabular}{|c|c|c|c|c|c|c|c|}
\hline \multirow[b]{2}{*}{ Polymer } & \multirow[b]{2}{*}{ Compound status } & \multicolumn{3}{|c|}{ Calcd. } & \multicolumn{3}{|c|}{ Found } \\
\hline & & $\% \mathrm{C}$ & $\% \mathrm{H}$ & $\% \mathrm{~N}$ & $\% \mathrm{C}$ & $\% \mathrm{H}$ & $\% \mathrm{~N}$ \\
\hline Poly(amic acid) & $\left(\mathrm{C}_{30} \mathrm{H}_{17} \mathrm{~N}_{5} \mathrm{O}_{8}\right)_{n}$ & $62 \cdot 61$ & 2.98 & $12 \cdot 17$ & 61.47 & $3 \cdot 16$ & $13 \cdot 33$ \\
\hline Polyimide & $\left(\mathrm{C}_{30} \mathrm{H}_{13} \mathrm{~N}_{5} \mathrm{O}_{6}\right)_{n}$ & $66 \cdot 79$ & $2 \cdot 43$ & $12 \cdot 98$ & $65 \cdot 70$ & $2 \cdot 04$ & $13 \cdot 87$ \\
\hline
\end{tabular}

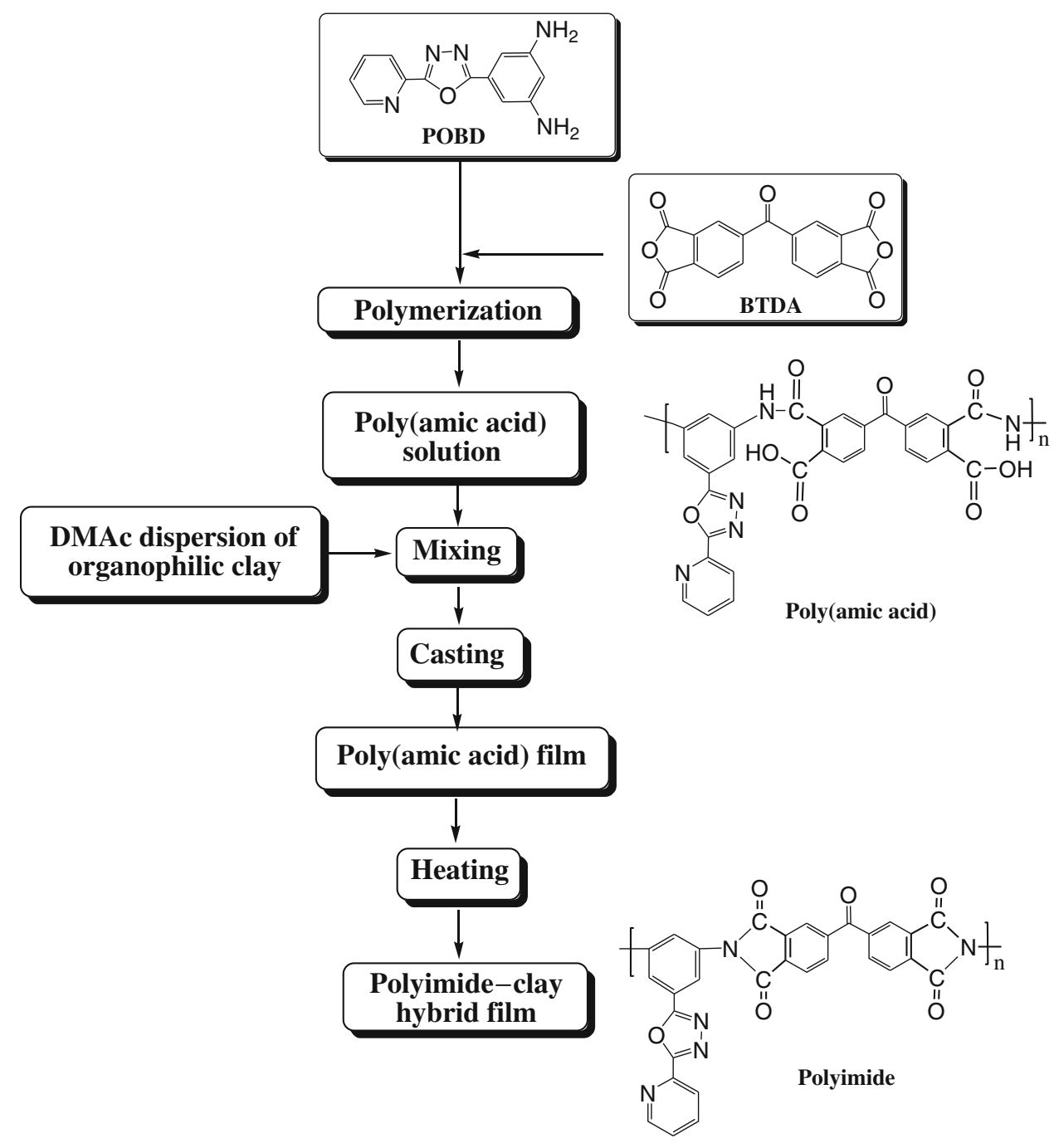

Scheme 3. Synthesis of polyimide/clay hybrids. 
where $\lambda$ is the $\mathrm{X}$-ray wavelength (1.5418 $\AA$ ). The measured $d$-spacing of Na MMT is $1.0 \mathrm{~nm}\left(2 \theta=8.76^{\circ}\right)$.

In general, a larger interlayer spacing should assist the intercalation of polymer chains. It should also lead to easier dissociation of the clay, which should result in hybrids with better clay dispersion. A strong peak appears at $2 \theta=3.17^{\circ}(d=2.6 \mathrm{~nm})$ representing diffraction from the $d_{001}$ crystal surface of Cloisite 20A. XRD pattern of PCN $1 \%$ does not show any diffraction peak, indicating that the silicate layers of organoclay have been either intercalated to a distance of more than $4.4 \mathrm{~nm}\left(2 \theta<2.0^{\circ}\right)$ or completely exfoliated. This observation reveals that the organophilic clay in this hybrid disperses homogeneously into the polyimide matrix. This homogeneous dispersion may be due to the existence of some physicochemical interactions between the polyimide and the organophilic clays.

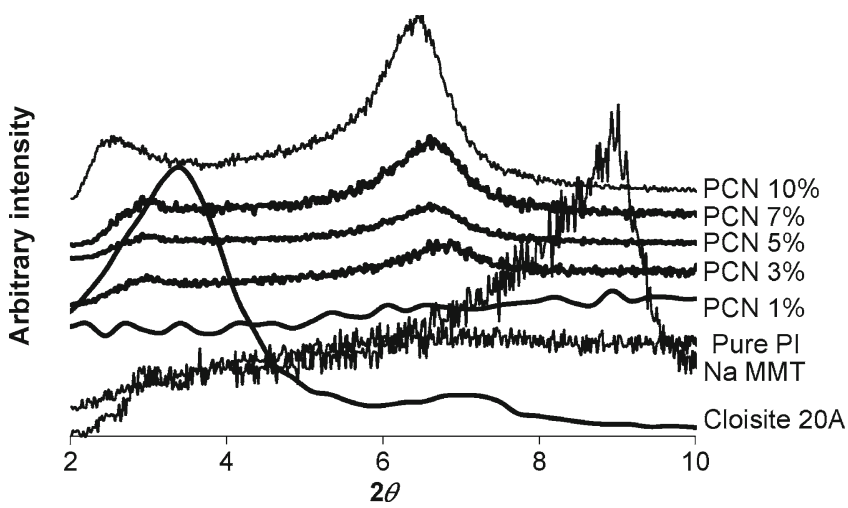

Figure 2. Wide-angle powder X-ray diffraction patterns of polyimide, Na MMT, Cloisite 20A and PCNs.
However, completely different results have been obtained with POBD-modified organoclay as surfactant and similar polyimide matrix. Even at low clay loading (PCN 1\%) intercalated nanocomposite has been obtained (Mansoori et al 2011a). This can be attributed to the large basal spacing of Cloisite 20A ( $d=3.42 \mathrm{~nm})$ when compared with the POBD-modified MMT $(d=1.33 \mathrm{~nm})$. A better diffusion of polymer chains in the organoclay gallery and platelets peel off occurs with Cloisite 20 A. The absence of any diffraction peak between 2 and $10^{\circ}$ is also observed for pure polyimide. Polyimide/clay nanocomposites of 3-10\% show two broad diffraction peaks. The presence of the slightly broader peak at $3.13-2.63^{\circ}(d \sim 2.8-3.4 \mathrm{~nm})$ indicates that partially intercalated organophilic clay layers are dispersed in the PI matrix. The second peak appears at 6.78-6.37 $(d \sim 1.3-1.4 \mathrm{~nm})$. In a very extensive study, Delozier et al (2007) proved that in the polyimide hybrids that contain clay modified with aliphatic quaternary ammonium salts, the observation of this peak is the consequence of the thermal decomposition of the organic cations. This phenomenon leads to collapsing of the clay layers that reduces the $d$-spacing and the formation of a collapsed agglomerated structure. The clay agglomerates apparently retained their original structure, and it is doubtful that they were impregnated by monomers prior to polymerization. Therefore, both intercalated/exfoliated and agglomerated structures are present in the nanocomposite with clay content higher than $1 \%$. A substantial increase in the intensities of the second XRD peak was observed for increase in the clay loading up to $10 \mathrm{wt} \%$, which suggests that the dispersion is better at a lower clay loading than at a higher clay loading. This observation also implies that there is no significant quantity of intercalated/exfoliated organoclay in the nanocomposites with high clay content, and the organoclay is mainly present

Table 4. Diffraction peaks and basal spacing of polyimide and PCNs.

\begin{tabular}{lcc}
\hline & \multicolumn{2}{c}{ Diffraction peak and basal spacing } \\
\cline { 2 - 3 } Product & Typical diffraction peak $\left({ }^{\circ}\right)^{\mathrm{b}}$ & Basal spacing $(\mathrm{nm})^{\mathrm{b}}$ \\
\hline Pure polyimide & - & - \\
Na MMT & 8.76 & 1.00 \\
Cloisite 20A & $3.42(6.90)^{\mathrm{c}}$ & $2.60(1.33)$ \\
aPCN 1\% & $-(6.64)$ & - \\
PCN 3\% & $3.13(6.56)$ & $2.80(1.35)$ \\
& 6.78 & 1.30 \\
PCN 5\% & $3.02(6.67)$ & $2.90(1.32)$ \\
& 6.62 & 1.30 \\
PCN 7\% & $3.02(6.70)$ & $2.90(1.32)$ \\
& 6.67 & 1.30 \\
PCN 10\% & 2.63 & 3.40 \\
& 6.37 & 1.40 \\
\hline
\end{tabular}

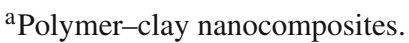

${ }^{b}$ Values in parentheses are obtained based on similar polymer matrix and POBD-modified MMT as surfactant (Mansoori et al 2011a).

${ }^{\mathrm{c}}$ POBD-modified MMT (Mansoori et al 2011a). 
in the form of collapsed agglomerates. The comparative XRD data are summarized in table 4.

Figure 3 depicts DSC-TGA thermograms for the polyimide. The polymer had the char yield, about $60.45 \%$ at $691{ }^{\circ} \mathrm{C}$. Glass transition temperature of the pure polyimide is observed at approximately $255^{\circ} \mathrm{C}$, and the polymer does not show any melting endotherm. As seen, no thermal degradation occurred until this temperature. The onset of decomposition of the polymer occurs at $420{ }^{\circ} \mathrm{C}$, and thermal decomposition does not occur below this temperature.

Figure 4 shows DSC curves of PI and PCNs, which were obtained after heating the samples to $200{ }^{\circ} \mathrm{C}$ and then cooling to room temperature. This heating and cooling cycle removed any trace of adsorbed water on the polymer. As shown in the figure, the $T_{\mathrm{g}}$ value increases dramatically from $255^{\circ} \mathrm{C}$ for pure polyimide to $300{ }^{\circ} \mathrm{C}$ for $\mathrm{PCN} 1 \%$, and then gradually increases to $335{ }^{\circ} \mathrm{C}$ for PCN $5 \%$. This means that, upon addition of organoclay into polyimide matrix, softening of the polymer occurs at elevated temperatures. This observation is tentatively attributed to the confinement of the

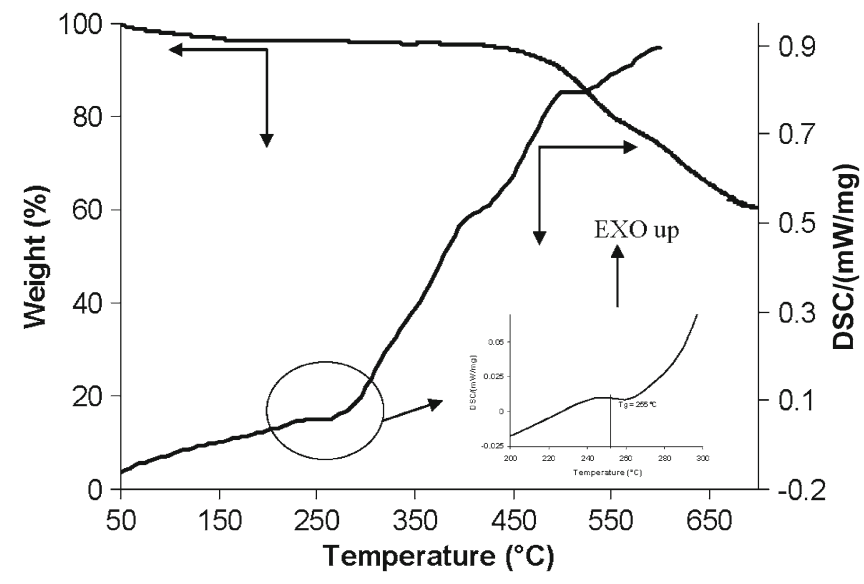

Figure 3. DSC-TGA curves (nitrogen atmosphere, scan rate $10^{\circ} \mathrm{C} / \mathrm{min}$ ) of the polyimide.

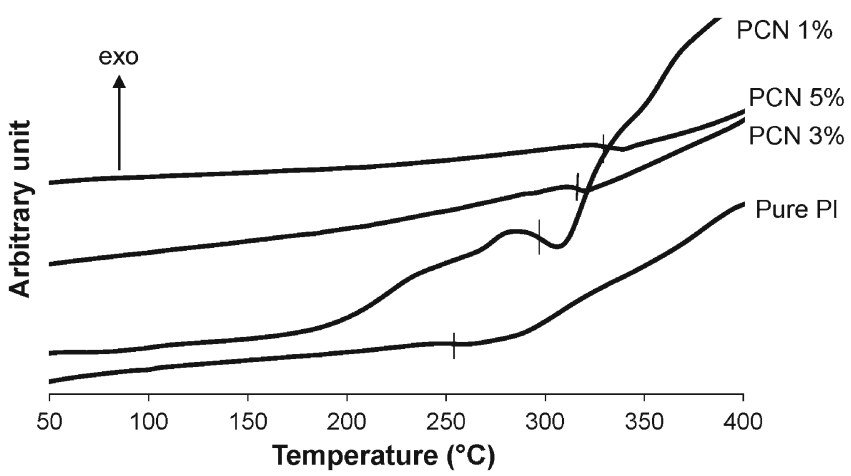

Figure 4. DSC curves (nitrogen atmosphere, scan rate $10^{\circ} \mathrm{C} / \mathrm{min}$ ) of PI and PCNs with various Cloisite 20A contents. intercalated polymer chains within the clay galleries, which prevents the segmental motions of the polymer chains (Yeh et al 2004). As seen, the increase of $T_{\mathrm{g}}$ value for PCNs obtained from Cloisite 20A is higher than that of PCNs obtained from POBD-treated MMT, specially at low clay loading (Mansoori et al 2011a). Based on WXRD measurements, this is due to the exfoliation and the existence of the strong interaction between Cloisite 20A platelets and polymer matrix at low clay loading. Glass transition temperature for nanocomposite materials with higher loadings is not observed.

TGA curves of the pure polyimide and nanocomposites with $1-10 \mathrm{wt} \%$ clay loadings are shown in figure 5 . The polymer had the highest char yield, about $73.79 \%$ at $600{ }^{\circ} \mathrm{C}$. All samples showed minimal weight loss at low temperatures, which can be attributed to the moisture collection resulting from the hygroscopic property of the polyamides. These results demonstrate that the prepared polymer and PCNs are hydrophilic, owing partly to the large number of nitrogen and oxygen atoms present in their structure. The decomposition onset temperature $\left(T_{\mathrm{D}}\right)$ increased as clay loading increased for PCNs $0-7 \%$ and then decreased. The $10 \%$ weight loss temperature also increased regularly for nanocomposites up to $0-5 \%$ clay loading and then decreased. This tendency may be due to the better miscibility of polymer/clay phases at low clay loadings. The obtained multilayered carbonaceous silicate structure may act as an excellent insulator and increase the total path of evaporation for small molecules generated during decomposition (Gilman et al 2000). At high clay loadings, coagulation may occur. Char yields at $600{ }^{\circ} \mathrm{C}$ are also increased with increasing organoclay loading. Initial weight loss before main chain decomposition is high for PCN 10\%. This observation may be attributed to the pyrolysis of quaternary alkyl ammonium salts, which is significant at higher clay contents. The results of the thermal analyses by TGA and DSC for PI and PCNs are summarized in table 5, and compared with our previously reported study (Mansoori et al 2011a). The obtained PCN films have very improved thermal stability than those nanocomposites obtained from POBD-MMT organoclay.

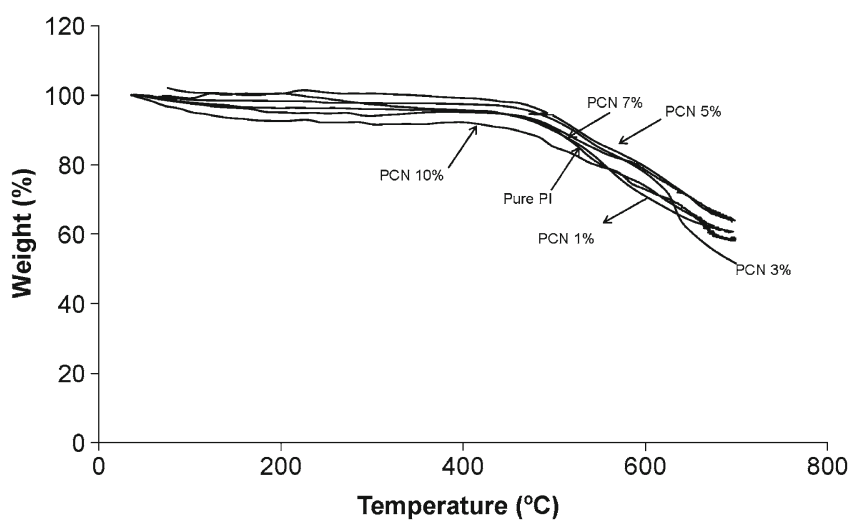

Figure 5. TGA curves of PI and PCNs with various Cloisite 20A contents. 
Scanning electron microscopy (SEM) was used to compare the surface morphology of nanocomposite films with the virgin polymer. Some significant changes were observed on the surface of PCN $1 \%$ with respect to the virgin polyimide film. As can be seen in the pictures, homogeneity and film surface continuation are diminished in PCN $1 \%$, and too many micro cracks are observed on the surface (figure $6(\mathrm{a}-\mathrm{b}))$.

Solvent uptake measurement was conducted by using two series of solvents. The first series consisted of conventional solvents such as water, ethanol and toluene, while the other series consisted of non-protonic polar solvents such as NMP,

Table 5. Thermal properties of polyimide and nanocomposites. ${ }^{\mathrm{a}}$

\begin{tabular}{llllll}
\hline Polymer & \multicolumn{1}{c}{$T_{\mathrm{g}}\left({ }^{\circ} \mathrm{C}\right)$} & $T_{\mathrm{m}}\left({ }^{\circ} \mathrm{C}\right)$ & $10 \%$ weight loss $\left({ }^{\circ} \mathrm{C}\right)$ & $T_{\mathrm{D}}\left({ }^{\circ} \mathrm{C}\right)^{\mathrm{b}}$ & Char yield $^{\mathrm{c}}$ \\
\hline Polyimide & 255 & N.D. $^{\mathrm{d}}$ & 500 & 420 & 73.79 \\
PCN 1\% & $300(283)$ & N.D. & $497(497)$ & $454(422)$ & $70.94(72 \cdot 79)$ \\
PCN 3\% & $315(281)$ & N.D. & $520(466)$ & $458(413)$ & $77.58(68 \cdot 25)$ \\
PCN 5\% & $335(280)$ & N.D. & $525(485)$ & $461(413)$ & $79 \cdot 25(70 \cdot 98)$ \\
PCN 7\% & N.D. (268) & N.D. & $504(472)$ & $465(413)$ & $78.43(70 \cdot 99)$ \\
PCN 10\% & N.D. (N.A. $)^{\text {e }}$ & N.D. & $456($ N.A. $)$ & 451 (N.A.) & 72.87 (N.A.) \\
\hline
\end{tabular}

${ }^{a}$ Values in parentheses are obtained based on similar polymer matrix and POBD-modified MMT as surfactant (Mansoori et al 2011a); ${ }^{b}$ onset decomposition temperature; ${ }^{\mathrm{c}}$ at $600{ }^{\circ} \mathrm{C}$; ${ }^{\mathrm{d}}$ not detected and ${ }^{\mathrm{e}}$ not analysed.

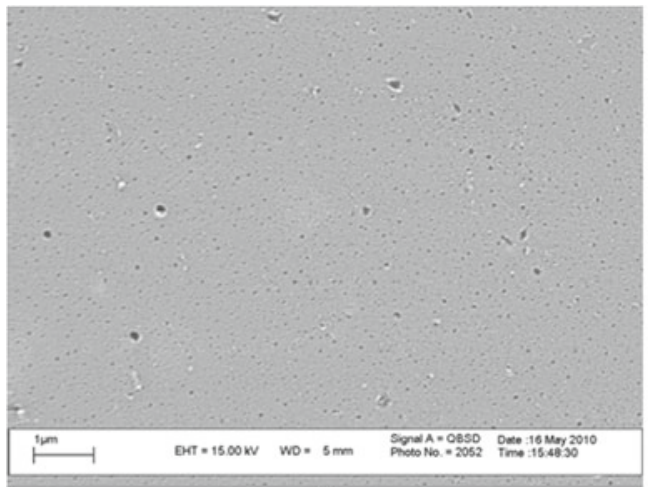

(a)

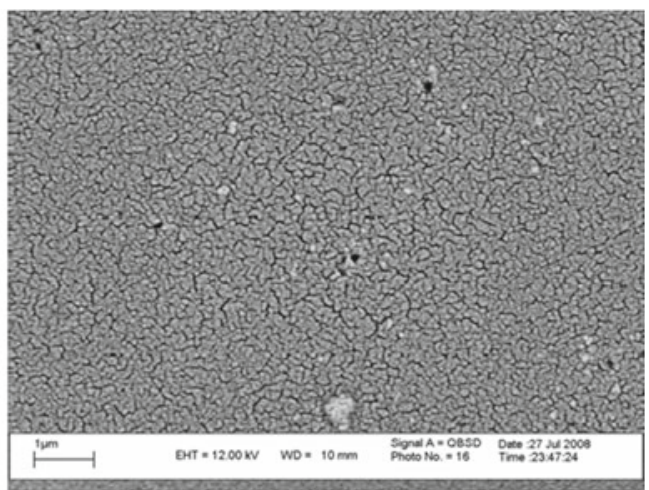

(b)

Figure 6. SEM images of films obtained from: (a) polyimide and (b) PCN $1 \%$ at $30000 \times$.

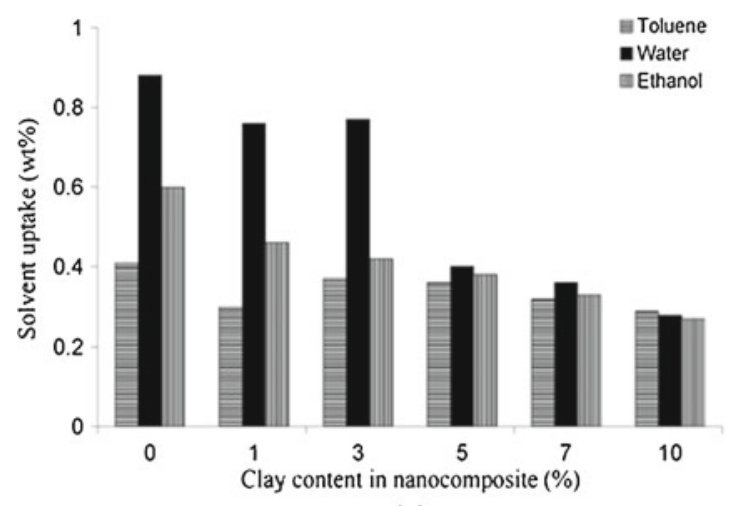

(a)

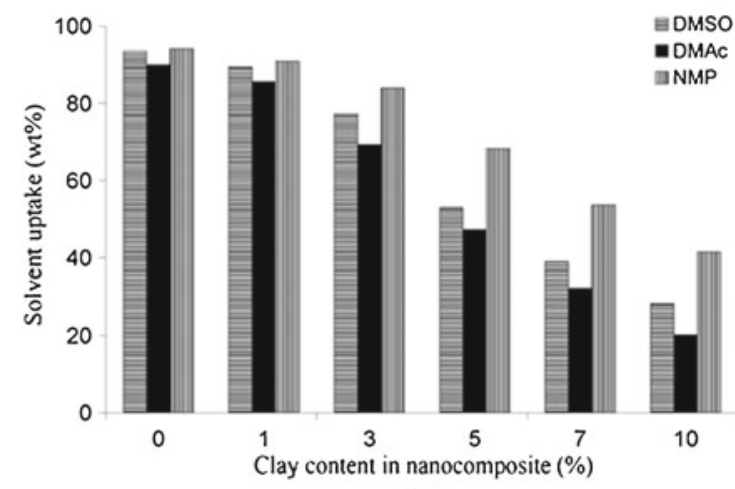

(b)

Figure 7. Solvent uptake of nanocomposites: (a) toluene, water and ethanol and (b) DMSO, DMAc and NMP. 
DMAc and DMSO. The results of the measurement are depicted in figure 7. In both cases, introduction of MMT leads to a clear decrease in the solvent uptake. Both polyimide and PCN materials showed small tendency $(<1 \%)$ towards the uptake of solvents of the first series (figure 7(a)). In this category, as the MMT content was increased from 0 to $10 \mathrm{wt} \%$, the water uptake decreased from 0.88 to $0.28 \%$. For the second series of solvents, a very dramatic decrease in the solvent uptake was observed for the PCN materials compared to the virgin PI. For example, the DMAc uptake drops from $90 \%$ in pure PI to about $20 \%$ in PCN $10 \%$ (figure 7(b)). This phenomenon can be attributed to the strong interaction between polymer and MMT and the excellent barrier properties of the large aspect ratio silicate that maximizes the available surface area of the reinforcing phase. The interaction between PI and MMT leads to the formation of 'bound polymer', polymer in close proximity to the reinforcing filler (MMT) that is either physisorbed or chemisorbed, and therefore, restricts the solvent uptake (Huang et al 2001).

\section{Conclusions}

New polyimide/clay nanocomposites have been obtained from thermal imidization of the organoclay dispersion of Cloisite $20 \mathrm{~A}$ in a poly(amic acid) solution. The solution has been prepared from the reaction between POBD and BTDA in DMAc. XRD patterns showed that exfoliated nanocomposite may be obtained with the organoclay content of $1 \%$, but at higher clay loadings, the intercalated structure is significant. TGA and DSC measurements showed that both thermal stability and glass transition temperature increased with increasing organoclay content. Comparison of the results with the results obtained for the same polyimide and POBD-modified organoclay as surfactant showed that the PCNs obtained in this study have improved thermal stability. SEM images showed that the surface roughness of the film obtained from nanocomposite $1 \%$ increased with respect to the virgin polymer.

\section{Acknowledgements}

The Graduate Council of University of Mohaghegh Ardabili (Iran) is gratefully acknowledged for financial support.

\section{References}

Chatzidaki E K, Favvas E P, Papageorgiou S K, Kanellopoulos N K and Theophilou N V 2007 Eur. Polym. J. 435010

Chi J H, Park S H, Lee C L, Kim J J and Jung J C 2007 Macromol. Mater. Eng. 292844

Chiang P-C and Whang W-T 2003 Polymer 442249
Delozier D M, Orwoll R A, Cahoon J F, Johnston N J, Smith Jr J G and Connell J W 2007 Polymer 43813

Ding J, Day M, Robertson G and Roovers J 2002 Macromolecules 353474

Du M, Li C P and Guo J H 2006 Inorg. Chim. Acta 3592575

Gandhi K S and Williams M C 1971 J. Polym. Sci.: Part C 35211

Gilman J W, Jackson C L, Morgan A B, Harris R, Manias Jr E, Giannelis E P, Wuthenow M, Hilton D and Phillips S H 2000 Chem. Mater. 121866

Gintert M J, Jana S C and Miller S G 2007 Polymer 484166

Gomes D and Nunes S P 2003 Macromol. Chem. Phys. 2042130

Gu A, Kuo S-W and Chang F-C 2001 J. Appl. Polym. Sci. 791902

Hsiao S-H and Chiou J-H 2001 J. Polym. Sci. Part A: Polym. Chem. 392271

Hsu S-L C and Fan M H 2004 Polymer 451101

Huang C-C, Jang G-W, Chang K-C, Hung W-I and Yeh J-M 2008 Polym. Int. 57605

Huang J-C, Zhu Z-K, Yin J, Qian X-F and Sun Y-Y 2001 Polymer 42873

Imai Y, Itoya K, Kanamaru M and Kakimoto M A 2002 J. Polym. Sci. Part A: Polym. Chem. 401790

Incarvito C and Rheingold A L 2001 Inorg. Chem. 401386

Jia Q-X, Wu Y-P, Wang Y-Q, Lu M and Zhang L-Q 2008 Compos. Sci. Technol. 681050

Jin H-S and Chang J-H 2008 J. Appl. Polym. Sci. 107109

Jin Qin C, Gavrilova Anna L and Bosnich B 2001 Inorg. Chem. 40 1386

Köytepe S, Gürbüz N, Özdemir I and Seckin T 2008 J. Inorg. Organomet. Polym. 18290

Liang Z-M, Yin J and Xu H-J 2003 Polymer 441391

Liaw D J and Liaw B Y 1998 Macromol. Chem. Phys. 1991473

Mansoori Y, Atghia S V, Shah Sanaei S, Zamanloo M R and Imanzadeh Gh 2010a Macromol. Res. 181174

Mansoori Y, Atghia S V, Zamanloo M R, Imanzadeh Gh and Sirousazar M 2010b J. Eur. Polym. 461844

Mansoori Y, Fathollahi K, Zamanloo M R and Imanzadeh Gh 2011a Polym. Compos. 321862

Mansoori Y, Shah Sanaei S, Atghia S V, Zamanloo M R and Imanzadeh Gh 2011b Chin. J. Polym. Sci. 29699

Mansoori Y, Koohi-Zargar B, Shekaari H, Zamanloo M R and Imanzadeh Gh 2012a Chin. J. Polym. Sci. 30112

Mansoori Y, Koohi-Zargar B, Shekaari H, Zamanloo M R and Imanzadeh Gh 2012b Polym. Bull. 68113

Mansoori Y, Atghia S V, Shah Sanaei S, Zamanloo M R, Imanzadeh Gh and Eskandari H 2012c Polym. Int. 611213

Mansoori Y, Sarvari R, Zamanloo M R and Imanzadeh Gh 2012d Chin. J. Polym. Sci. 2821

Matsumoto N, Hiruma H, Nagaoka S, Fujiyama K, Kaneko A and Kawakami H 2008 Polym. Adv. Technol. 191002

Morgan A B and Gilman J W 2003 J. Appl. Polym. Sci. 871329

Nguyen L T T, Nguyen H N and La T H T 2007 Opt. Mater. 29610

Njuguna J, Pielichowski K and Desai S 2008 Polym. Adv. Technol. 19947

Phang I Y, Liu T, Mohamed A, Pramoda K P, Chen L, Shen L, Chow S Y, He C, Lu X and Hu X 2005 Polym. Int. 54456

Rubal M, Wilkins Jr C W, Cassidy P E, Lansford C and Yamada Y 2008 Polym. Adv. Technol. 191033

Shin T J, Park H K, Lee S W, Lee B, Oh W, Kim J S, Baek S, Hwang Y T, Kim H C and Ree M 2003 Polym. Eng. Sci. 431232

Souza Jr F G, Sena M E and Soares B G 2004 J. Appl. Polym. Sci. 931631 
Stefanescu E A, Stefanescu C, Daly WH, Schmidt G and Negulescu I I 2008 Polymer 493785

Tyan H-L, Wei K-H and Hsieh T-E $2000 \mathrm{~J}$. Polym. Sci. Part B: Polym. Phys. 382873

Xu S G, Yang M J and Bai F L 2003 Synth. Met. 1371097

Yano K, Usuki A and Okada A 1997 J. Polym. Sci. A: Polym. Chem. 352289
Yano K, Usuki A, Okada A, Kurauchi T and Kamigaito O 1993 J. Polym. Sci. Part B: Polym. Phys. 312493

Yeh J M, Liou S J and Chang Y W 2004 J. Appl. Polym. Sci. 91 3489

Yudin V E, Otaigbe J U, Gladchenko S, Olson B G, Nazarenko S, Korytkova E N and Gusarov V V 2007 Polymer 481306

Zhao X-Y and Wang M-Z 2006 J. Appl. Polym. Sci. 1003116 